\title{
THE IMPACTS OF POLICY REFORM ON INFORMATION DIFFUSION IN CHINESE REAL ESTATE STOCKS
}

\author{
Dong Chi \\ Hebei University \\ Zamri Ahmad* \\ Universiti Sains Malaysia \\ Yang Yang \\ China Minsheng Bank, Shijiazhuang
}

\begin{abstract}
The study focuses on the process of information diffusion in Chinese real estate stocks. By investigating whether and how policy reforms that occurred during 2002 to 2013 affected the process of information diffusion, this study finds there is a significant lead-lag relationship between big and small Chinese real estate stocks, generated by the gradual information diffusion. This study further discovers that this lead-lag effect is enhanced along with main policy reforms of Chinese real estate market during the full sample period, which implies the delay degree of information diffusion becomes greater over time. Therefore, policy reforms in Chinese real estate market increase friction of information diffusion. However, continuously decreasing information volatility of information diffusion suggests information environment and transparency of market have improved over time. Therefore, the results support the notion that, along with the market development, policy reforms of Chinese real estate market have brought about transparency to the market to some degree.
\end{abstract}

Keywords: Policy Reform; Information Diffusion; Real Estate Stocks; China.

\section{INTRODUCTION}

Lo and MacKinlay (1990) discover information gradually diffuses in financial market, which is contrary to the Efficient Market Hypothesis (EMH) that states information instantaneously diffuses in an efficient market. Abundant researches continually provide evidences to support the gradual information diffusion in the market (Brennan et al., 1993; Badrinath et al., 1995; Hong and Stein, 1999; Chordia and Swaminathan, 2000; Hou, 2007; Cohen and Frazzini, 2008; Menzly and Ozbas, 2010; Mori, 2015). Importantly, by examining information diffusion in U.S. market, Hou (2007) argues the phenomenon of gradual information diffusion mainly appears intra-industry rather than cross industry or outside industry. He further implies intra-industry information diffusion is more significant in some industries such as Real Estate Investment Trusts (REITs). However, previous researches that focus on firms within industry to investigate the process of information diffusion are still lacking, especially for emerging markets. Chinese real estate market provides suitably empirical study area. Thus, this paper aims to examine the gradual information diffusion in Chinese real estate market.

\footnotetext{
* Corresponding author: Zamri Ahmad, School of Management, Universiti Sains Malaysia, 11800 Minden, Penang, Malaysia.. Email: zahmad@usm.my
} 
Additionally, as an important setting of market environment, policy reforms of government have significant impacts to market on various aspects. Merton (1987) recognizes the importance of institutional restrictions in the information acquisition and dissemination process. Market environment and institutional arrangement could be responsible for the speed of information diffusion. As one of recent research hotspots, policy reforms have an effect on the process of information diffusion. Qiao et al. (2008) and Chiang et al. (2008) argue that policy reforms affect the process of information diffusion among Chinese segmented stock markets. They claim the impacts of policy reforms are significant to the process of information diffusion. Mori (2015) investigates whether policy reforms in the REIT market influence information diffusion among REIT stocks in US. By analyzing time-series changes of lead-lag effect, he finds changes of the process of information diffusion depend on different government policies and changes of firm size. At present, there are no REITs in China, but many Chinese real estate companies are listed on China stock exchanges. They are the dominant sector of the market. Hence, it is suitable to investigate Chinese real estate market in terms of information diffusion and impact of policy reform.

As the second largest economic power and the biggest emerging market in the world, China's economy attracts more and more attention from the world. With the rapid economic development, it is widely accepted that the real estate industry is an important booster for the recent China economic development, especially after the Housing Policy reform in 1998 (Deng et al., 2009). From 1998 to 2016, the investment capital on the real estate industry increased thirty folds, from 300 billion RMB to 10.2 trillion $\mathrm{RMB}$, compared with other industries where average investment capital only increased at lesser rate (National Bureau of Statistics of China. (2016). Chinese real estate industry receives enormous attention from all walks of life. Since Chinese Housing Policy reform in 1998, housing price in China has displayed a dramatic growth. Xu and Chen (2012) show housing prices in part of first-tier cities even have increased more than eightfold since 1998. With the constant increase of housing prices and the worry about property price bubble, Chinese government continuously introduces policy packages including land policy, monetary policy, property tax policy and affordable housing policy to control housing price.

Among these policy reforms, the policies of "state of eight" introduced in 2006 and "state of ten" introduced in 2010 are most well-known and significant. The main objective of "state of eight" is to regulate the housing structure and curb housing prices fast growth such as the introduction of a land value-added tax, strict control of public financing of listed real estate companies, increasing the two suites loan rates and other suppressive policies. On the other hand, "state of ten" might be the most dramatic tightening policy up to now. For example, the down payment rate is raised from $20 \%$ to $30 \%$ for all first time home buyers. The mortgage rate discount is reduced from $30 \%$ to $15 \%$ of the benchmark interest rate. Moreover, the same family is prohibited from purchasing second or third houses. Speculative purchases of housing are restricted. In spite of a series of policy packages introduced to Chinese real estate market, questions remain as to whether these policy reforms are effective. Zhang et al. (2012) argue these administrative measures might cool Chinese real estate market in the short term, but whether they are effective in the long run is still questionable. Therefore, further investigation is necessary.

One area of study under real estate investment investigates the speed of information diffusion. Some researches examine the process of information diffusion, with a focus on the linkage between real estate returns and real estate stocks. For example, by investigating the time-series change of momentum effect in REITs, Chui et al. (2003) find speed of information diffusion is more influenced by investor overconfidence than informational efficiency. Zhang and Deng (2010) discover that contrarian profits could be partly explained by the lead-lag effects for hotel real estate stocks. 
Based on the above brief introduction, this present study investigates the impacts of policy reforms on the process of information diffusion in the real estate companies' stocks in China. Specifically, this study investigates two issues. First, it examines whether a significant lead-lag effect is evident among Chinese real estate stocks, which implies the gradual information diffusion. Second, during the period of 2002 to 2013, the study investigates whether policy reforms that occurred have affected the process of information diffusion among Chinese real estate stocks over time, and how the reforms give the impact.

The empirical results of the study show there is a significant lead-lag relationship between the lagged returns of big Chinese real estate stocks and the current returns of small Chinese real estate stocks during 2010-2013, generated by the gradual information diffusion. Moreover, This study further discover this lead-lag effect is enhanced along with main policy reforms of Chinese real estate market during the full sample period, which implies the delay degree of information diffusion becomes greater over time. Therefore, policy reforms in Chinese real estate market increase friction of information diffusion. However, continuously decreasing information volatility of information diffusion suggests information environment and transparency of market have improved over time. Therefore, the results support the notion that, along with the market development, policy reforms of Chinese real estate market have brought about transparency to the market to some degree.

\section{DATA}

Flourishing period of Chinese real estate industry began from Housing Policy reform in 1998. Listing date of many Chinese real estate stocks started from 2001. However, as a new market, China stock market which was established in 1990, saw stock prices fluctuate excessively in the initial ten years. For the purpose of obtaining relatively stable data, the initial years of China stock market are excluded in the study. Therefore, it is decided that the full study period will be from January 2002 to December 2013. After 2002, the number of listed Chinese real estate firms ranged from 115 in 2002 to 127 in 2013.

Data for this study include daily closing real estate companies' stock prices, daily closing Chinese real estate Index, and firms' market capitalization, covering the period from January 2001 to December 2013. All data are obtained from Thomson Financial DataStream and China Securities Registration and Settlement Statistical Yearbook 2001-2013. China Securities Registration and Settlement Statistical Yearbook is the official publication of China Securities Depository and Clearing Corporation Limited.

In order to avoid the substantial bias associated with nonsynchronous trading and some microstructure effects at the daily level, weekly returns are employed in the underlying analyses. In addition, seasonal patterns might affect weekly autocorrelations of stock returns. According to Hou (2007), autocorrelations based on Friday close are too high and autocorrelations based on Tuesday closes are too low, while autocorrelations of weekly returns ending on Wednesdays are in the middle. Thus, we calculate the weekly returns from Wednesday close to the following Wednesday close. The summary statistics are described in following table.

Table 1 displays the summary statistics for equal-weighted size portfolios for the sample period of 2002 to 2013. There are 626 weekly observed values in each size portfolio. As showed in the table, the average weekly return of the largest $30 \%$ firms equals 0.0008 , while the average weekly return of the smallest $30 \%$ firms is 0.0038 . Obviously, small firms' return is greater than the large firms' return. Moreover, the standard deviation of the smallest $30 \%$ firms' return is 0.045 , which is greater than that in the largest $30 \%$ firms' return (0.044). These results imply small firm have higher risk, but they also have higher return. Table 2 presents the results of unit root test including the ADF and PP test. We find unit root test 
that rejects the null hypothesis at the $1 \%$ level, which exhibits these time-series data are stationary and can be contained in the further time-series analysis.

Table 1: Descriptive Statistics

\begin{tabular}{cccccccc}
\hline \hline Portfolio & Mean & Std & Median & Max & Min & ADF test & PP test \\
\hline $\mathrm{R}_{\mathrm{B}}$ & 0.0008 & 0.044 & -0.0005 & 0.2722 & -0.1709 & $-10.418^{* * *}$ & $-24.783^{* * *}$ \\
$\mathrm{R}_{\mathrm{S}}$ & 0.0038 & 0.045 & 0.0026 & 0.1576 & -0.2376 & $-23.369^{* * *}$ & $-23.577 * * *$ \\
\hline \hline
\end{tabular}

Notes: $\mathrm{R}_{\mathrm{B}}$ and $\mathrm{R}_{\mathrm{S}}$ refer to the largest $30 \%$ portfolio and the smallest $30 \%$ portfolio in Chinese real estate stocks, respectively.

Table 2: Unit root test

\begin{tabular}{ccccccccccc}
\hline \hline Portfolio & $\boldsymbol{\rho}_{0}(\mathbf{j}, \mathbf{B})$ & $\boldsymbol{\rho}_{\mathbf{0}}(\mathbf{j}, \mathbf{S})$ & $\boldsymbol{\rho}_{1}(\mathbf{j}, \mathbf{B})$ & $\boldsymbol{\rho}_{1}(\mathbf{j}, \mathbf{S})$ & $\boldsymbol{\rho}_{2}(\mathbf{j}, \mathbf{B})$ & $\boldsymbol{\rho}_{2}(\mathbf{j}, \mathbf{S})$ & $\boldsymbol{\rho}_{3}(\mathbf{j}, \mathbf{B})$ & $\boldsymbol{\rho}_{3}(\mathbf{j}, \mathbf{S})$ & $\boldsymbol{\rho 4}_{4}(\mathbf{j}, \mathbf{B})$ & $\boldsymbol{\rho 4}_{4}(\mathbf{j}, \mathbf{S})$ \\
\hline $\mathrm{R}_{\mathrm{B}, \mathrm{t}}$ & 1 & 0.814 & 0.124 & -0.082 & 0.123 & 0.053 & 0.043 & -0.049 & 0.008 & -0.013 \\
$\mathrm{R}_{\mathrm{S}, \mathrm{t}}$ & 0.913 & 1 & 0.083 & 0.106 & -0.045 & 0.100 & 0.057 & 0.065 & 0.017 & 0.037 \\
\hline \hline
\end{tabular}

Notes: $\rho_{\mathrm{m}}(\mathrm{j}, \mathrm{k}), \mathrm{m}=0$ to $4, \mathrm{j}=\mathrm{B}$ or $\mathrm{S}$, and $\mathrm{k}=\mathrm{B}$ or $\mathrm{S}$, is correlation coefficient. $\mathrm{B}$ and $\mathrm{S}$ refer to the largest $30 \%$ size portfolio and the smallest $30 \%$ size portfolio, respectively. $\rho_{\mathrm{m}}(\mathrm{j}, \mathrm{k})$ refers to the $\mathrm{m}^{\text {th }}$ order correlation coefficient between returns on the largest $30 \%$ portfolio and the smallest $30 \%$ portfolio. For example, $\rho 1(\mathrm{~S}, \mathrm{~B})$ denotes the correlation between week t return on the smallest $30 \%$ portfolio and week $\mathrm{t}-1$ return on the largest $30 \%$ portfolio. And $\rho 2(\mathrm{~B}, \mathrm{~S})$ represents the correlation between week $\mathrm{t}$ return on the largest $30 \%$ portfolio and week $\mathrm{t}-2$ return on the smallest $30 \%$ portfolio. On the other hand, $\rho_{\mathrm{m}}(\mathrm{j}, \mathrm{k})$ also displays autocorrelation of portfolios' return. For instance, $\rho 1(B, B)$ refers to the first-order autocorrelation of the largest $30 \%$ portfolio. $\rho 4(S, S)$ means the fourth-order autocorrelation of the smallest $30 \%$ portfolio.

Autocorrelation matrices displays the results of the first through fourth order autocorrelations and cross autocorrelations. The first-order autocorrelation coefficient declines as we move from the smallest firms to the largest firms. When longer lags from 2 to 4 weeks for smallest and largest firms are examined, the autocorrelation function declines fast. On the other hand, the first order correlation coefficient between returns on the lagged large firms and the current small firms $(0.083)$ is higher than the first order correlation coefficient between on the lagged small firms and the current large firms (-0.082). As more lags come, the coefficients of cross autocorrelation decay. Therefore, the cross autocorrelation between big firms' lagged returns and small firms' current returns is greater than the cross autocorrelation between small firms' lagged returns and big firms' current returns. This asymmetric cross autocorrelations are consistent with the hypothesis of gradual information diffusion: when new information comes, small firms react more slowly than big firms (e.g., Lo and MacKinlay, 1990). However, the above analyses do not control for own autocorrelation effects. The cross autocorrelation pattern could also be consistent with an alternative hypothesis rooted in time-varying expected returns (e.g., Conrad and Kaul, 1988; Boudoukh et al., 1994). Consequently, the above evidence of asymmetric cross autocorrelations are not sufficient to strongly support the information-based hypothesis for the lead-lag effect. Thus, next analyses will control the autocorrelations of small firms.

\section{INFORMATION DIFFUSION IN CHINESE REAL ESTATE STOCKS}

Vector-autoregressive regression (VAR) tests are formally employed to investigate information diffusion in Chinese real estate stocks. Chordia and Swaminathan (2000) state VAR model not only proves whether big firms' lagged returns lead small firms' current returns, but more importantly, it can provide a kind of measure about the speed of information diffusion. The corresponding VAR model is described in the following equations:

$$
\mathrm{R}_{\mathrm{S}, \mathrm{t}}=\mathrm{a}_{0}+\sum_{k=1}^{K} a_{k} \quad \mathrm{R}_{\mathrm{S}, \mathrm{t}-\mathrm{k}}+\sum_{k=1}^{K} b_{k} \quad \mathrm{R}_{\mathrm{B}, \mathrm{t}-\mathrm{k}}+\mathrm{u}_{\mathrm{t}}
$$


$\mathrm{R}_{\mathrm{B}, \mathrm{t}}=\mathrm{c}_{0}+\sum_{k=1}^{K} c_{k} \quad \mathrm{R}_{\mathrm{S}, \mathrm{t}-\mathrm{k}}+\sum_{k=1}^{K} d_{k} \quad \mathrm{R}_{\mathrm{B}, \mathrm{t}-\mathrm{k}}+\mathrm{v}_{\mathrm{t}}$

In equation (1) and (2), $\mathrm{R}_{\mathrm{S}, \mathrm{t}}$ and $\mathrm{R}_{\mathrm{S}, \mathrm{t}-\mathrm{k}}$ are the equal-weighted weekly return on the smallest $30 \%$ portfolio at period $\mathrm{t}$ and period $\mathrm{t}-\mathrm{k}$, while $\mathrm{R}_{\mathrm{B}, \mathrm{t}}$ and $\mathrm{R}_{\mathrm{B}, \mathrm{t}-\mathrm{k}}$ present the equal-weighted weekly return on the largest $30 \%$ portfolio at period $\mathrm{t}$ and period $\mathrm{t}-\mathrm{k}$. In the VAR setting, $\sum_{k=1}^{k} a_{k}$ and $\sum_{k=1}^{k} d_{k}$ denote the degree about own autocorrelations of small firms and big firms, respectively. $\sum_{k=1}^{k} b_{k}$ and $\sum_{k=1}^{k} c_{k}$ refer to the impact of lagged big firms' returns on current small firms' returns and the impact of lagged small firms' returns on current big firms' returns, correspondingly.

Particularly, if there is no lead-lag effect between big and small firms, the $\sum_{k=1}^{k} b_{k}$ should equal to zero. It implies lagged big firms' returns has no impacts on current small firms' returns. Explaining from other aspect, we presume the cross-autocorrelations between $R_{S}$ and $R_{B}$ are merely due to autocorrelations of $R_{S}$, coupled with contemporaneous correlation between $R_{S}$ and $R_{B}$. When the explanatory power of the lagged $\mathrm{R}_{S}$ is constrained, the lead-lag relation should disappear. In other words, the cross-autoregressive coefficients i.e. $\sum_{k=1}^{k} b_{k}$ in the VAR should be zero. Consequently, if there is the lead-lag relation between big and small firms, which is generated by gradual information diffusion, we expect the sum of coefficients $\sum_{k=1}^{k} b_{k}$ to be greater than zero i.e. $\sum_{k=1}^{k} b_{k}>0$.

Based on Brennan et al. (1993), we employ the test of cross-equation null hypothesis: $\sum_{k=1}^{k} b_{k}=\sum_{k=1}^{k} c_{k}$ to estimate whether one portfolio' lagged return can predicts another portfolio' current return. In this case, if the source of cross-autocorrelation between big and small firms is big firms' faster respond to information than small firms, big firms' lagged returns ought to have enough predictive ability for small firms' current returns. Specifically, if the lead-lag relation between big and small firms is driven by a gradual diffusion of information from big firms to small firms, in the context of the VAR, we expect the sum of coefficients $\sum_{k=1}^{k} b_{k}$ to be greater than the sum of coefficients $\sum_{k=1}^{k} c_{k}$ i.e. $\sum_{k=1}^{k} b_{k}>\sum_{k=1}^{k} c_{k}$.

Next step, before VAR estimation, we should first decide on the selection of lag in VAR model. The selection results are stated in the following table.

Table 3: Selection of lag for VAR estimation

\begin{tabular}{ccccccc}
\hline \hline Lag & LogL & LR & FPE & AIC & SC & HQ \\
\hline 0 & 2141.961 & NA & $1.76 \mathrm{e}-06$ & -7.5750 & $-7.5597^{*}$ & -7.5690 \\
1 & 2153.460 & 22.8761 & $1.71 \mathrm{e}-06$ & -7.6016 & -7.5555 & -7.5836 \\
2 & 2165.862 & 24.5841 & $1.66 \mathrm{e}-06$ & -7.6313 & -7.5546 & $-7.6014^{*}$ \\
3 & 2172.088 & 1.95664 & $1.67 \mathrm{e}-06$ & -7.6286 & -7.4904 & -7.5746 \\
4 & 2173.082 & 12.2975 & $\mathbf{1 . 6 5 e - 0 6 *}$ & $\mathbf{- 7 . 6 3 9 2 *}$ & -7.5317 & -7.5973 \\
5 & 2173.921 & 1.64406 & $1.69 \mathrm{e}-06$ & -7.6174 & -7.4485 & -7.5515 \\
6 & 2174.782 & 1.68237 & $1.70 \mathrm{e}-06$ & -7.6063 & -7.4067 & -7.5284 \\
7 & 2175.850 & 2.08023 & $1.72 \mathrm{e}-06$ & -7.5959 & -7.3656 & -7.5060 \\
8 & 2182.993 & $13.8553^{*}$ & $1.70 \mathrm{e}-06$ & -7.6070 & -7.3460 & -7.5051 \\
\hline \hline
\end{tabular}

As seen in the Table 3, Minimum value of Akaike Information Criterion (AIC) equals -7.6392 in four lag. Minimum value of Final Prediction Error (FPE) is $1.65 \mathrm{e}-06$ in four lag. Both AIC and FPE information criterions support the four-lag to be adaptive order criteria. Thus, four-lag is used in vector model. Consequently, the following analysis is based on 4-lag vector model.

Table 4 displays the empirical results of the VAR model based on weekly return on the size portfolios for the period from 2002 to 2013 (626 weeks) in Chinese real estate stocks. In order to better observe 
the results of vector-auto regressions, we also show one-lag vector-auto regression. In one-lag VAR, $\mathrm{b}_{1}$ equals 0.148 , while $c_{1}$ is -0.139 . Both of them are significant at $10 \%$ level. Obviously, the former is greater than the latter. It suggests big firm have more impacts on small firms, controlling for the effects of autocorrelation. Furthermore, we move to four-lag VAR. $\sum_{\mathrm{K}=1}^{4} b_{k}$ equals 0.462 and is bigger than that in one-lag VAR. It implies there is still some delayed price response further than one week. Alternatively, $\sum_{\mathrm{K}=l}^{4} c_{k}$ is -0.401 . Therefore, the impacts of big firm on small firms are greater than the impacts of small firm on big firms, controlling for the effects of autocorrelation. Moreover, they are statistically significant at the $1 \%$ level. Additionally, the F-statistic for the cross-equation test is also rejected at the $1 \%$ level for the one-lag regressions $(\mathrm{F}=12.220)$ and four-lag $(\mathrm{F}=37.180)$. These results show there is a noticeable lead-lag relation between big and small firms within the Chinese real estate industry. Furthermore, this lead-lag effect reflects the gradual information diffusion from big to small firms. The results further imply big firms have faster speed of information diffusion than small firms within the Chinese real estate market.

Table 4: Lead-lag effect for the full sample period

\begin{tabular}{|c|c|c|c|c|c|c|}
\hline \multirow[t]{2}{*}{ Dependent } & \multicolumn{2}{|c|}{$\begin{array}{c}\text { 1-Lag } \\
\text { Regressions }\end{array}$} & \multirow{2}{*}{$\begin{array}{c}\begin{array}{c}\text { Cross-equation } \\
\text { test }\end{array} \\
\mathrm{b}_{1}=\mathrm{c}_{1} \\
\end{array}$} & \multicolumn{2}{|c|}{$\begin{array}{c}\text { 4-Lag } \\
\text { Regressions }\end{array}$} & \multirow{2}{*}{$\begin{array}{c}\begin{array}{c}\text { Cross-equation } \\
\text { Test }\end{array} \\
\sum_{\mathrm{K}=1}^{4} b_{k}=\sum_{\mathrm{K}=l}^{4} c_{k}\end{array}$} \\
\hline & $\mathrm{R}_{\mathrm{S},(\mathrm{t}-1)}$ & $\mathrm{R}_{\mathrm{B},(\mathrm{t}-1)}$ & & $\sum_{\mathrm{K}=1}^{4} \mathrm{R}_{\mathrm{S},(\mathrm{t}-\mathrm{k})}$ & $\sum_{\mathrm{K}=1}^{4} \mathrm{R}_{\mathrm{B},(\mathrm{t}-\mathrm{k})}$ & \\
\hline \multirow{2}{*}{ Rs } & -0.073 & 0.148 & $12.220 * * *$ & -0.204 & 0.462 & $37.180 * * *$ \\
\hline & -0.897 & $1.748^{*}$ & & $3.317 * *$ & $12.087^{* * *}$ & \\
\hline \multirow{2}{*}{$\mathrm{R}_{\mathrm{B}}$} & -0.139 & 0.117 & & -0.401 & 0.516 & \\
\hline & $-1.975 *$ & 1.442 & & $10.261 * * *$ & $14.347 * * *$ & \\
\hline
\end{tabular}

$\overline{\text { Notes: Dependent denotes the dependent variable. } \mathrm{R}_{\mathrm{S}, \mathrm{t}} \text { and } \mathrm{R}_{\mathrm{S}, \mathrm{t}-\mathrm{k}} \text { are the equal-weighted weekly return on the smallest } 30 \% \text { portfolio }}$ at period $t$ and period $t-k$, while $R_{B, t}$ and $R_{B, t-k}$ present the equal-weighted weekly return on the largest $30 \%$ portfolio at period $t$ and period t-k. The F-statistics (t-statistics) for the null hypothesis that the sum of the coefficients equals 0 in the 4-lag (1-lag) VAR is displayed under the corresponding coefficient. Cross-equation test denotes F-statistic for the cross-equation null hypothesis in 1lag and 4-lag regressions. Finally, ${ }^{* * *}, * *$, and $*$ denote significance at the 1,5 , and $10 \%$ levels, respectively.

\section{POLICY REFORMS AND INFORMATION DIFFUSION IN CHINESE REAL ESTATE MARKET}

Based on a series of policy reforms of Chinese real estate market, there are two most important policy reforms: "state of eight" in 2006 and "state of ten" in 2010. These special time points become the two break points. Therefore, the full sample period is divided into three sub-periods (according to year and month): 2002.01-2006.01, 2006.02-2010.01 and 2010.02-2013.04. In order to detect the impacts of policy reforms on information diffusion in Chinese real estate market, we process the separate estimations in these three sub-periods. The empirical results are summarized in Table 4.

Table 5 displays the separate VAR estimations in these three sub-periods. $\sum_{\mathrm{K}=1}^{4} b_{k}$ is $0.244,0.547$ and 0.564 in three sub-periods, respectively. Moreover, they increase over time and only significant at $1 \%$ level in the latter two sub-periods. Therefore, the impacts of the big firms' lagged returns on the small firms' current returns become bigger from the first sub-period to the third sub-period. The results suggest the lead-lag effect that is driven by the gradual diffusion of information from big firms to small firms become stronger over time. Thus, information diffusion from big firms to small firms becomes slower over time. As a result, the policy reforms of Chinese real estate market indeed influence the information dissemination among Chinese real estate stocks. Due to the policy reforms, more delay is brought into the procedure of information dissemination over time. 
Table 5: VAR estimations in three sub-periods

\begin{tabular}{|c|c|c|c|c|c|c|c|c|c|}
\hline \multirow{2}{*}{ Dependent } & \multicolumn{3}{|c|}{ 2002.01-2006.01 } & \multicolumn{3}{|c|}{ 2006.02-2010.01 } & \multicolumn{3}{|c|}{ 2010.02-2013.04 } \\
\hline & $\sum_{\mathrm{K}=1}^{4} \mathbf{R}_{\mathrm{S},(\mathrm{t}-\mathrm{k})}$ & $\sum_{\mathrm{K}=1}^{4} \mathbf{R}_{\mathbf{B},(\mathrm{t}-\mathrm{K})}$ & F-test & $\sum_{\mathrm{K}=1}^{4} \mathbf{R}_{\mathbf{S},(\mathrm{t}-\mathrm{k})}$ & $\sum_{\mathrm{K}=1}^{4} \mathbf{R}_{\mathbf{B},(\mathrm{t}-\mathrm{k})}$ & F-test & $\sum_{\mathrm{K}=1}^{4} \mathbf{R}_{\mathbf{S}, \mathbf{t}-\mathrm{k}}$ & $\sum_{\mathrm{K}=1}^{4} \mathbf{R}_{\mathbf{B},(\mathrm{t}-\mathrm{k})}$ & F-test \\
\hline \multirow{2}{*}{ Rs } & -0.512 & 0.244 & 1.275 & -0.285 & 0.547 & $19.662 * * *$ & -0.312 & 0.564 & $41.796^{* * * *}$ \\
\hline & $4.108 * *$ & 0.669 & & 1.361 & $4.569 * *$ & & $4.478 * *$ & $11.808 * * *$ & \\
\hline \multirow{2}{*}{$\mathrm{R}_{\mathrm{B}}$} & -0.227 & 0.197 & & -0.606 & 0.777 & & -0.482 & 0.614 & \\
\hline & 1.028 & 0.579 & & $7.060 * * *$ & $9.941 * * *$ & & $12.126 * * *$ & $16.968 * * *$ & \\
\hline
\end{tabular}

Notes: F-test denotes F-statistic for the cross-equation null hypothesis in four-lag regression.

In the next step, we explore more details about impacts of policy reforms, whereby VAR procedure continues to be employed to estimate the time-series reforms of lead-lag effect during the whole sample period. We use Mori's (2015) method, which considers the quarterly lead-lag effect from big firms to small firms controlling for the reverse the lead-lag effect from small firms to big firms. Therefore, onelag panel VAR structure is adopted, as estimation aims at each quarter. Particularly, one-lag VAR model is stated in the following equations:

$$
\begin{aligned}
& R_{S, t}=a_{0}+a_{1} R_{S, t-1}+b_{1} R_{B, t-1}+u_{t} \\
& R_{B, t}=c_{0}+c_{1} R_{S, t-1}+d_{1} R_{B, t-1}+v_{t}
\end{aligned}
$$

In equation (3) and (4), $b_{1}$ and $c_{1}$ respectively is the coefficient of lagged returns of big firms and small firms. Moreover, $b_{1}$ and $c_{1}$ denote the impact of lagged big firms' returns on current small firms' returns and the impact of lagged small firms' returns on current big firms' returns, correspondingly. We will estimate the effect of the subtraction of $b_{1}$ and $c_{1}$ i.e. $\left(b_{1}-c_{1}\right)$. The subtraction of $\mathrm{b}_{1}$ and $\mathrm{c}_{1}$ evaluates the lead-lag effect from big firms to small firms, while controlling for the reverse lead-lag effect from small firms to big firms. Specifically, we will focus on the coefficient i.e. $\left(b_{1}-c_{1}\right)$ in the full study period. First, the quarterly time-series changes of the lead-lag effect are stated in the following Figure.

Figure 1: The quarterly time-series changes of the lead-lag effect

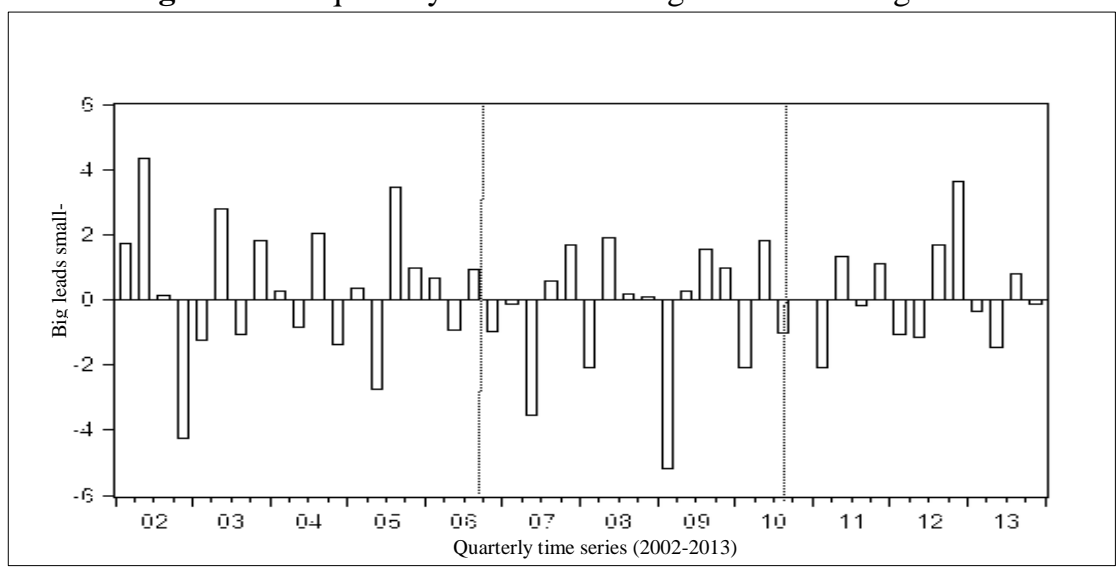

Figure 1 shows the quarterly time-series changes of the lead-lag effect that is driven by the gradual information diffusion from big firms to small firms. Each bar equals the subtraction of $b_{1}$ and $c_{1}$ in quarterly estimation. Horizontal axis is time-series quarters from 2002 to 2013. Fig.1 also displays the 
whole variation trend of size and volatility of quarterly lead-lag effects from 2002 to 2013 . Next step, we further explore the subtraction of $b_{1}$ and $c_{1}$ to investigate the impacts of policy reforms on information dissemination in Chinese real estate market. The empirical results are showed in the following table.

Table 6: The quarterly time-series lead-lag reforms in the three sub-periods

\begin{tabular}{cccccc}
\hline \hline Sub-period & Mean & Std & Skewness & Max & Min \\
\hline $2002.01-2006.01$ & -0.303 & 1.612 & -0.093 & 3.051 & -3.526 \\
$2006.02-2010.01$ & 0.521 & 0.920 & -0.516 & 1.733 & -1.564 \\
2010.02-2013.04 & 0.532 & 0.683 & 0.259 & 1.670 & -0.425 \\
F-test & $\mathbf{2 . 7 5 9 *}$ & $\mathbf{1 0 . 4 2 5 * * *}$ & & & \\
\hline \hline
\end{tabular}

Notes: Mean denotes mean of $\left(\mathrm{b}_{1}-\mathrm{c}_{1}\right)$ in the sub-period. Std refers to standard deviation of $\left(\mathrm{b}_{1}-\mathrm{c}_{1}\right)$ in the sub-period. F-test refers to F-statistics for mean compare and variance compare among three sub-periods. ***, **, and * denote significance at the 1,5 , and $10 \%$ levels, respectively.

Table 6 sums up the subtraction of $b_{1}$ and $c_{1}$ in quarterly lead-lag effects among three sub-periods in Chinese real estate stocks. First, mean of $\left(b_{1}-c_{1}\right)$ actually describes the average size of quarterly leadlag effect in the sub-period. According to table 5 , mean of three sub-periods respectively is $-0.303,0.521$ and 0.532 . They become bigger over time. It suggests the quarterly lead-lag effects develop stronger from the first sub-period to the last sub-period. Moreover, F-statistic for the comparison of mean is 2.795 and significant at the $10 \%$ level, which suggests the difference of mean really exists among three subperiods. It implies the average size of quarterly lead-lag effect is actually different in these three subperiods. Thus, information diffusion is also dissimilar in different sub-periods. As a result, the results display delay degree of information diffusion from big stocks to small stocks becomes greater over time. These results further imply the speed of intra-industry information diffusion between big and small stocks declines along with the policy reforms of China stock market. Therefore, policy reforms impede information diffusion in Chinese real estate market.

On the other hand, standard deviation of $\left(b_{1}-c_{1}\right)$ actually shows the volatility of quarterly lead-lag effect in the sub-period. As stated in table 6, standard deviation of three sub-periods respectively is 1.612 , 0.920 and 0.683 . They show a downtrend over time. Moreover, F-statistic about the comparison of standard deviation is 10.425 and significant at the $1 \%$ level, which suggests the difference of standard deviation actually exists among three sub-periods. The results present the volatility of quarterly lead-lag effects decrease over time. Therefore, magnitude of fluctuation of information diffusion obviously reduces over time. Consequently, these results suggest the information volatility declines along with the policy reforms of Chinese real estate market.

Additionally, we also consider the changes of market conditions of Chinese real estate market in the three sub-periods. The results are described in the table below.

Table 7 describes the comparisons of different market conditions among three sub-periods in Chinese real estate market. As shown in Table 7, the number of Chinese real estate stocks is growing over time, which suggests the booming development of the Chinese real estate market. Difference of lead-lag refers to the subtraction of $b_{1}$ and $c_{1}$, which measures the quarterly lead-lag effect. Rising mean of Degree-lead implies increasing delay of intra-industry information diffusion, while declining standard deviation of Degree-lead suggests volatility degree of information diffusion decreases continuously. Therefore, these results show, along with the market development and policy reforms in Chinese real estate market, the delay degree of intra-industry information diffusion becomes bigger over time. Therefore, policy reforms in Chinese real estate market enhance friction of information diffusion and look like ineffective in some degree. However, continuously decreasing information volatility of information diffusion 
suggests policy reforms are useful from other aspect. With policy reforms of Chinese real estate market, information environment and transparency of market have improved over time. More or less informational efficiency and transparency are brought into Chinese real estate market. Therefore, the results also support, policy reforms of Chinese real estate market is acceptable in some degree.

Table 7: Comparison of real estate market conditions among three sub-periods

\begin{tabular}{|c|c|c|c|c|c|c|}
\hline \multirow{2}{*}{ Variables } & \multirow{2}{*}{ Mean } & \multirow{2}{*}{ Std } & \multirow{2}{*}{ Min } & \multirow{2}{*}{$\operatorname{Max}$} & \multicolumn{2}{|c|}{ F-test } \\
\hline & & & & & Mean & Variance \\
\hline \multicolumn{7}{|c|}{ Sub-period1: 2002.01-2006.01 } \\
\hline Difference of lead-lag & -0.303 & 1.612 & -3.526 & 3.051 & $2.759 *$ & $10.425^{* * *}$ \\
\hline RE index & 1501 & 471.3 & 790 & 2254 & $11.685 * * *$ & $47.683 * * *$ \\
\hline Return of RE & -0.072 & 0.136 & -0.301 & 0.253 & $2.455^{*}$ & $10.604 * * *$ \\
\hline Number of RE & 117 & 1.267 & 115 & 119 & $112.12 * * *$ & $31.458 * * *$ \\
\hline \multicolumn{7}{|c|}{ Sub-period 2 : 2006.02-2010.01 } \\
\hline Difference of lead-lag & 0.521 & 0.920 & -1.564 & 1.733 & & \\
\hline RE index & 3536 & 1942 & 949 & 7382 & & \\
\hline Return of RE & 0.09 & 0.293 & -0.671 & 0.532 & & \\
\hline Number of RE & 122 & 2.318 & 119 & 126 & & \\
\hline \multicolumn{7}{|c|}{ Sub-period3 : 2010.02-2013.04 } \\
\hline Difference of lead-lag & 0.532 & 0.683 & -0.425 & 1.670 & & \\
\hline RE index & 3305 & 316 & 2749 & 3829 & & \\
\hline Return of RE & -0.018 & 0.103 & -0.334 & 0.24 & & \\
\hline Number of RE & 126 & 0.414 & 126 & 127 & & \\
\hline
\end{tabular}

Notes: RE index is Chinese real estate stocks index. Return of RE the total return of the Chinese real estate stocks index. Number of RE is the number of Chinese real estate stocks. F-test refers to F-statistics for mean compare and variance compare among three sub-periods. $* * *, * *$, and $*$ denote significance at the 1,5 , and $10 \%$ levels, respectively.

\section{CONCLUSION AND DISCUSSION}

The empirical results of the study show there is a significant lead-lag relationship between the lagged returns of big Chinese real estate stocks and the current returns of small Chinese real estate stocks during 2010-2013, generated by the gradual information diffusion. Moreover, this study further discovers that this lead-lag effect is enhanced along with main policy reforms of Chinese real estate market during the full sample period, which implies the delay degree of information diffusion becomes greater over time. Therefore, policy reforms in Chinese real estate market increase friction of information diffusion. However, continuously decreasing information volatility of information diffusion suggests information environment and transparency of market have improved over time. Therefore, the results support the notion that, along with the market development, policy reforms of Chinese real estate market have brought about transparency to the market to some degree.

\section{REFERENCES}

Badrinath, S. G., Kale, J. R., \& Noe, T. H. (1995). Of shepherds, sheep, and the cross-autocorrelations in equity returns. Review of Financial Studies, 8(2), 401-430.

Boudoukh, J., Richardson, M., \& Whitelaw, R. (1994). Industry returns and the fisher effect. Journal of Finance, 49(5), 1595-1615.

Brennan, M. J., Jegadeesh, N., \& Swaminathan, B. (1993). Investment analysis and the adjustment of stock prices to common information. Review of Financial Studies, 6(4), 799-824. 
Chiang, T. C., Nelling, E., \& Tan, L. (2008). The speed of adjustment to information: Evidence from the Chinese stock market. International Review of Economics \& Finance, 17(2), 216-229.

Chordia, T., \& Swaminathan, B. (2000). Trading volume and cross-autocorrelations in stock returns. The Journal of Finance, 55(2), 913-935.

Chui, A. C., Titman, S., \& Wei, K. (2003). Intra-industry momentum: the case of REITs. Journal of Financial Markets, 6(3), 363-387.

Cohen, L., \& Frazzini, A. (2008). Economic links and predictable returns. Journal of Finance, 63(4), 1977-2011.

Deng, L., Qingyun, S., \& Lin, W. (2009). Housing policy and finance in China: A literature review. Retrieved from http://citeseerx.ist.psu.edu/viewdoc/download?doi=10.1.1.455.8500\&rep=rep1\&type=pdf

Hong. H., \& Stein, J. C. (1999). A unified theory of underreaction, momentum trading, and overreaction in asset markets. Journal of Finance, 54(6), 2143-2184.

Hou, K. (2007). Industry information diffusion and the lead-lag effect in stock returns. Review of Financial Studies, 20(4), 1113-1138.

Kang, J., Liu, M.-H., \& Ni, S. X. (2002). Contrarian and momentum strategies in the China stock market: 1993-2000. Pacific-Basin Finance Journal, 10(3), 243-265.

Lo, A. W., \& MacKinlay, A. C. (1990). When are contrarian profits due to stock market overreaction? Review of Financial Studies, 3(2), 175-205.

Menzly, L., \& Ozbas, O. (2010). Market segmentation and cross-predictability of returns. Journal of Finance, 65(4), 1555-1580.

Merton, R. C. (1987). A simple model of capital market equilibrium with incomplete information. The Journal of Finance, 42(3), 483-510.

Mori, M. (2015). Information Diffusion in the US Real Estate Investment Trust Market. The Journal of Real Estate Finance and Economics, 51(2), 190-214.

National Bureau of Statistics of China. (2016). China Statistical Yearbook 2016. China: China Statistics Press.

Qiao, Z., Li, Y., \& Wong, W.-K. (2008). Policy change and lead-lag relations among China's segmented stock markets. Journal of Multinational Financial Management, 18(3), 276-289.

$\mathrm{Xu}, \mathrm{X}$. E., \& Chen, T. (2012). The effect of monetary policy on real estate price growth in China. Pacific-Basin Finance Journal, 20(1), 62-77.

Zhang, M., \& Deng, Y. (2010). Is the mean return of hotel real estate stocks apt to overreact to past performance? The Journal of Real Estate Finance and Economics, 40(4), 497-543.

Zhang, Y., Hua, X., \& Zhao, L. (2012). Exploring determinants of housing prices: A case study of Chinese experience in 1999-2010. Economic Modelling, 29(6), 2349-2361. 